\title{
Prediction of perineal tear during childbirth by assessment of striae gravidarum score
}

\author{
Shital Kapadia ${ }^{1}$, Swena Kapoor ${ }^{1}$, Kartikeya Parmar $^{2}$, Kavita Patadia ${ }^{3}$, Monark Vyas ${ }^{3}$ \\ ${ }^{1}$ Department of Obstetrics \& Gynecology, B. J. Medical College, Ahmedbad-16, Gujarat, India \\ ${ }^{2}$ Department of Medicine, B. J. Medical College, Ahmedbad-16, Gujarat, India \\ ${ }^{3}$ Department of Preventive and Social Medicine, B. J. Medical College, Ahmedbad-16, Gujarat, India
}

Received: 5 February 2014

Received: 19 February 2014

Accepted: 25 February 2014

\section{*Correspondence:}

Dr. Shital Kapadia,

E-mail: sheetalobgy@gmail.com

(C) 2014 Kapadia S et al. This is an open-access article distributed under the terms of the Creative Commons Attribution Non-Commercial License, which permits unrestricted non-commercial use, distribution, and reproduction in any medium, provided the original work is properly cited.

\begin{abstract}
Background: The objective of this study was to explore the association between striae gravidarum and the risk for perineal tear during childbirth.

Methods: Three hundred patients delivered normally were included in this study. Striae gravidarum score was assessed using the Atwal numerical scoring system. The association was examined between striae and perineal tear as the outcome measure, defined by tears or laceration, and the total striae scores (TSS) was obtained.

Results: Mean age was 25.41 years ranging from 20 - 30 years, mean gravidity was 2.27 ranging from 1 - 5, mean weight gain was $9.72 \mathrm{Kg}$ ranging from $5-16 \mathrm{Kgs}$ and average baby birth weight was $2.8 \mathrm{Kg}$ ranging from $2.1-3.5$ $\mathrm{Kg}$. The only predictors of perineal tears that were found to be statistically significant in our study were Severity of striae gravidarum and Episiotomy given or not. In patients with moderate to severe striae there was tear in 105 patients as compared to 45 patients with no or mild striae. 89 patients belonging to no or mild striae group delivered without any perineal tear whereas 61 patients in moderate to severe striae group delivered without perineal tear. It is observed that episiotomy has some protective effect against perineal tear.

Conclusions: This study demonstrates a significant relation between severity of striae gravidarum and perineal tear. The findings suggest that striae gravidarum assessment may be used in the clinical setting even by paramedical staff as a simple and noninvasive tool to better define women at risk for perineal tear.
\end{abstract}

Keywords: Striae gravidarum, Perineal tear, Episiotomy

\section{INTRODUCTION}

Perineal trauma is common during vaginal birth and can range from minor mucosal lacerations to severe injury that involves the musculature of the perineum and rectum. ${ }^{1}$ Perineal trauma may be associated with several complications including hemorrhage, perineal pain, dyspareunia, rectovaginal fistulae, perineal abscess and incontinence. Such complications are found to have a major negative effect on physical, psychological, social aspects and quality of life. Episiotomy as an intervention to avoid perineal tear is debatable. ${ }^{2}$ Therefore, better prediction of women at risk for spontaneous perineal tear is needed to improve the outcome of vaginal childbirth. ${ }^{3}$

Abdominal stretch marks found during pregnancy may be indicative of poor skin elasticity. One who does not have stretch marks may have better skin elasticity and may be less likely to tear perineal and vaginal tissue during vaginal delivery. This study was conducted to determine whether striae gravidarum could predict lacerations and their severity. During a normal vaginal birth, the fetal head exerts significant pressure on the tissues of the perineum and vaginal vault. Some women seem to have tissue that tears easily, even with a small baby and 
apparently easy birth. Others will give birth over intact perineum in spite of large babies or unusual presentations. If the same midwife uses approximately the same perineal protection techniques with each birth but gets very different perineal outcomes, one must assume that there are other factors besides perineal management at work. Techniques, size, and presentation of the baby those are also important in the ability to maintain an intact perineum during birth.

Striae gravidarum (SG) is a common phenomenon of stretch marks observed during pregnancy that may be an indicator of poor skin elasticity. The type and amount of collagen in connective tissue are considered to determine the individual's elastic index. The skin surface is made up of a complex network of crossing thin lines. The twodimensional relationship between primary and secondary lines determines the skin texture and its grade of irregularity. ${ }^{4,5}$ Striae gravidarum is caused by changes in the structural connective tissue due to a hormonal elect on the alignment and reduced elastin and fibrillin in the dermis. $^{6}$

This correlational research will examine the contribution of a woman's connective tissue elasticity as a factor in maintaining an intact perineum during birth, using abdominal striae as the marker variable for connective tissue elasticity. It is important to investigate if there might be any relationship of skin type to perineal integrity, so as to help in making decisions regarding the woman's care during childbirth. This study was designed to identify factors for determining this and particularly whether abdominal striae gravidarum can predict the likelihood and severity of tear.

\section{METHODS}

To test our hypothesis that those with few or no striae gravidarum are less likely to tear significantly and to determine whether there are other factors that can help predict laceration at the time of delivery, we did a cross sectional study. Three hundred patients delivered normally were included in this study, according to the following inclusion criteria: a) non-instrumental vaginal child birth b) term delivery c) singleton pregnancy d) neonatal birth weight $<4 \mathrm{~kg}$ and $>2 \mathrm{~kg}$ e) vertex presentation. This observational cross sectional Study was performed for the period of three months from August 2012 to October 2012 in a medical college affiliated tertiary care centre.

All women were examined in the maternity ward 1 to 2 days after the delivery. The assessment of striae gravidarum was performed by the single resident in all the women, who was blind to the information about whether the suturing had been performed. Severity scoring of striae gravidarum was observed using the numerical scoring system of Atwal. ${ }^{7}$ This scale provides a rank based on observation of four areas in which SG is most commonly observed (abdomen, hips, buttocks, and breast) the scale comprises the following criteria (a) the number of striae gravidarum at each body site $(0=$ no striae signs, $1=1-4$ striae, $2=5-10$ striae, $3=$ more than 10 striae) and (b) the color of the striae gravidarum which ranges from pale to purple $(0=$ no redness, $1=$ pink, $2=$ dark red, $3=$ purple). The final score for each body site, relating to number and color, ranges from 0 to 6 . Accordingly, the TSS (total striae score) for all four body sites ranges from 0 to 24 . Women having TSS score up to 12 were considered to be having mild striae, 13-18 TSS score indicated moderate striae and more than 18 TSS Score indicated severe striae. Later the same resident collected all medical, obstetric and demographic data from medical files. Included in the database were age, parity, race, weight gain, medical problems, number of previous vaginal deliveries, the fetal position, weight, mode of delivery, and degree of emergency, perineal tear (location and degree), episiotomy and extension data were noted.

The data entered into Epi Info 7 statistical analysis software package and Chi- square test on the various risk factors and delivery outcomes was done. Variables statistically significant in predicting lacerations namely striae gravidarum score and episiotomy were analyzed.

\section{RESULTS}

In present study population mean age was 25.41 years ranging from 20 - 30 years, mean gravidity was 2.27 ranging from $1-5$, mean weigh gain was $9.72 \mathrm{Kg}$ ranging from 5 - $16 \mathrm{Kgs}$ and average baby birth weight was $2.8 \mathrm{Kg}$ ranging from $2.1-3.5 \mathrm{Kg}$ (Table 1 ).

Table 1: Descriptive statistics for the study group $(\mathrm{N}=$ 300).

\begin{tabular}{|llll|}
\hline Variables & Mean & $\begin{array}{l}\text { Standard } \\
\text { deviation }\end{array}$ & Range \\
\hline Age (years) & 25.41 & 2.79 & $20-30$ \\
\hline Gravidity & 2.27 & 1.16 & $1-5$ \\
\hline Wt. gain $(\mathrm{Kg})$ & 9.72 & 2.12 & $5-16$ \\
\hline Baby wt. $(\mathrm{Kg})$ & 2.79 & 0.32 & $2.1-3.5$ \\
\hline
\end{tabular}

Figure 1 depicts the division of the study group into four categories namely those with no striae, mild striae, moderate striae and severe striae on the basis of the total striae score. It is evident from the chart that maximum patients $(41 \%)$ belonged to the moderate striae group whereas only $12 \%$ and $14 \%$ had no striae and severe striae respectively (Figure 1).

Various factors associated with perineal tears are described in Table 2. Variables such as severity of striae, delivery type (slow or rapid), delivery conducted by (junior or senior resident), Fetal position (occipito anterior or occipito posterior), episiotomy (given or not given) and baby weight were taken into consideration and their statistical significance was calculated. 


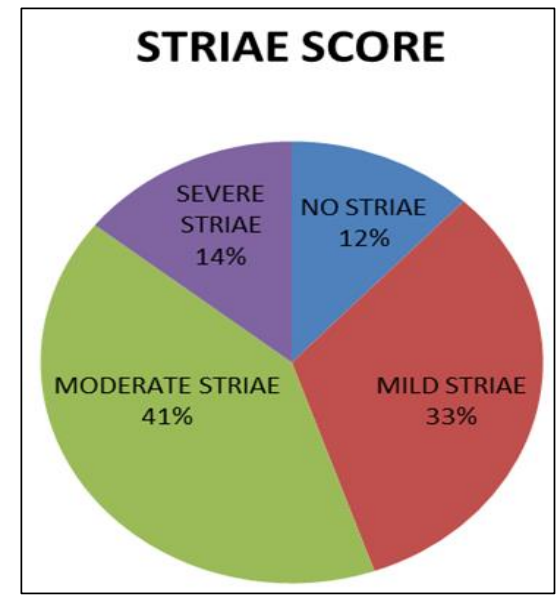

Figure 1: Severity of striae gravidarum according to striae score.

Table 2: Factors associated with perineal tear.

\begin{tabular}{|c|c|c|c|}
\hline & $\begin{array}{l}\text { No } \\
\text { perineal } \\
\text { tear }\end{array}$ & $\begin{array}{l}\text { Perineal } \\
\text { tear }\end{array}$ & $\begin{array}{l}\mathbf{P} \\
\text { value }\end{array}$ \\
\hline Striae & & & $0.00^{*}$ \\
\hline No striae & 21 & 15 & \\
\hline Mild (TSS up to 12) & 68 & 30 & \\
\hline Moderate (TSS 13-18) & 56 & 67 & \\
\hline Severe $(\mathrm{TSS}>18)$ & 5 & 38 & \\
\hline Delivery type & & & 0.248 \\
\hline Controlled, Slow & 138 & 132 & \\
\hline Rapid, Emergency & 12 & 18 & \\
\hline Conducted by & & & 0.105 \\
\hline Junior resident & 73 & 87 & \\
\hline Senior resident & 77 & 63 & \\
\hline Fetal position & & & 0.198 \\
\hline Occipito anterior & 147 & 143 & \\
\hline Occipito posterior & 03 & 07 & \\
\hline Episiotomy & & & $0.00^{*}$ \\
\hline Given & 63 & 10 & \\
\hline Not given & 87 & 140 & \\
\hline Baby weight (Kg) & & & 0.368 \\
\hline $2.1-2.5$ & 25 & 29 & \\
\hline $2.5-3$ & 92 & 80 & \\
\hline$>3$ & 33 & 41 & \\
\hline
\end{tabular}

The only predictors of perineal tears that were found to be statistically significant in our study were Severity of striae gravidarum and Episiotomy given or not. Even though tears were found more in patients delivered by junior doctors but it was not found to be statistically significant. Out of the 300 patients studied only 10 patients had occipito - posterior position. In our study no statistically significant relation was found between baby weights with perineal tears.
Table 3: Episiotomy versus perineal tear according to severity of striae gravidarum.

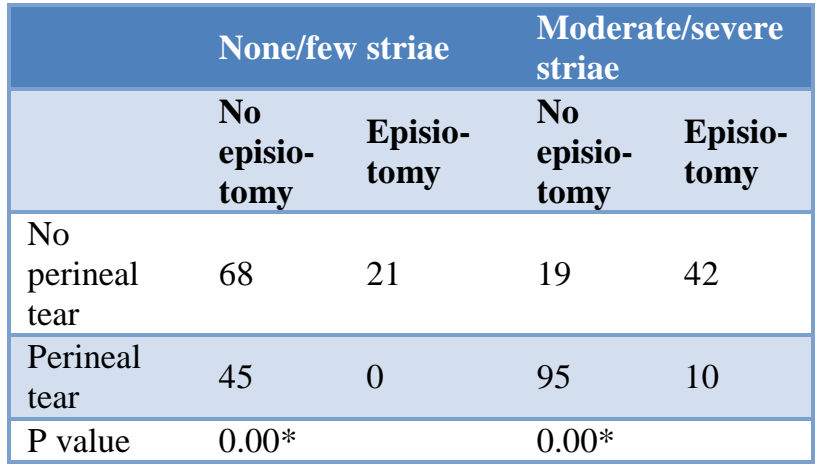

It is also observed that there is statistically significant correlation between perineal tear and severity of striae gravidarum. In patients with moderate to severe striae there was tear in 105 patients as compared to 45 patients with no or mild striae. 89 patients belonging to no or mild striae group delivered without any perineal tear whereas 61 patients in moderate to severe striae group delivered without perineal tear. Out of these 61 patients 42 were given episiotomy.

Table 4: Episiotomy versus perineal tear.

\begin{tabular}{|llll|}
\hline & $\begin{array}{l}\text { No } \\
\text { perineal } \\
\text { tear }\end{array}$ & $\begin{array}{l}\text { Perineal } \\
\text { tear }\end{array}$ & $\begin{array}{l}\text { P } \\
\text { value }\end{array}$ \\
\cline { 1 - 2 } Episiotomy & & \\
\cline { 1 - 2 } Given & 63 & 10 & \\
\hline Not given & 87 & 140 & \\
\hline
\end{tabular}

10 patients who were given episiotomy had perineal tear as compared to 140 patients who were not given episiotomy.

\section{DISCUSSION}

Primary aim of this study was to determine whether Total Striae Score can be used as a predictor of perineal tear at the time of vaginal delivery. Therefore, Total Striae Score can be used as an additional valuable predictor of the risk for perineal tear.

Striae gravidarum is common occurrence during pregnancy, though its severity is not considered as a medical condition in any clinical relevance for consideration in routine follow-up practice. It develops after 24 weeks of gestation. It has been reported that previous occurrence of striae on the breasts or thighs, family history of striae and race are significant predictors of striae development. ${ }^{5}$ Previous studies have demonstrated that maternal age, baseline and delivery BMI, neonatal birth weight, length and head circumference were independently associated with the occurrence of striae. ${ }^{7}$ Many factors have an impact on whether patients have perineal tears at the time of delivery. These factors are outlined in Table 2. Variables 
such as severity of striae, delivery type (slow or rapid), delivery conducted by (junior or senior resident), Fetal position (occipito anterior or occipito posterior), episiotomy (given or not given) and baby weight were taken into consideration and their statistical significance was calculated.

The only predictors of perineal tears that were found to be statistically significant in our study were severity of striae gravidarum and episiotomy given or not. Even though tears were found more in patients delivered by junior doctors but it was not found to be statistically significant. Out of the 300 patients studied only 10 patients had occipito - posterior position. In our study no statistically significant relation was found between baby weights with perineal tears. This observation does not correlate with the study conducted by Angioli and Gomez et al. ${ }^{8}$

It is also observed that there is statistically significant correlation between perineal tear and severity of striae gravidarum. In patients with moderate to severe striae there was tear in 105 patients as compared to 45 patients with no or mild striae. 89 patients belonging to no or mild striae group delivered without any perineal tear whereas 61 patients in moderate to severe striae group delivered without perineal tear. Out of these 61 patients 42 were given episiotomy, so in our study it is observed that episiotomy has some protective effect against tear. 10 patients who were given episiotomy had perineal tear as compared to 140 patients who were not given episiotomy. This shows that patients who had an episiotomy were less likely to have perineal tear in most cases.

In the past numerous controlled trials have compared outcomes in two groups - one in which episiotomy is given only for fetal or maternal indication or to prevent perineal tear $^{9-13}$. Still the use of liberal episiotomy to prevent perineal tear is debatable (Table 4). Previous research has shown that morbidity is higher in those with an episiotomy that in those without one. Any predictors that can help determine who can deliver without an episiotomy should be investigated to better guide physician in deciding who needs an episiotomy.

Several limitations in this study should be noted. First, the study was observational rather than an interventional design that may reduce the ability to emphasize the findings. Second data related to any previous episiotomy was missing in multiparae patients. Greater tendency to perform episiotomy in primigravida patients may limit the findings.

\section{CONCLUSIONS}

The foremost finding of our study is that an assessment of striae gravidarum appears to predict the occurrence of perineal tears. Striae score should be thus part of obstetrical assessment of the patients in the third trimester of pregnancy because such scores can be obtained with a simple and noninvasive observation. Paramedical staff in peripheral centers can also be trained to calculate the total striae score which can help them decide if episiotomy is to be given or not. Episiotomy definitely seems to be preventive for perineal tears but giving episiotomy for the same is still debatable as episiotomy in itself is associated with morbidity. But in this study it is observed that episiotomy given in patients with moderate to severe striae gravidarum definitely protects against perineal tears.

Funding: No funding sources

Conflict of interest: None declared

Ethical approval: The study was approved by the institutional ethics committee

\section{REFERENCES}

1. Arkin AE, Chern-Hughes B. Case report: Labial fusion postpartum and clinical management of labial lacerations. Journal of Midwifery and Women's Health. 2002;47:290-2.

2. Andrews V, Thakar R, Sultan AH, Jones PW. Evaluation of postpartum perineal pain and dyspareunia: a prospective study. Eur J Obstet Gynecol Reprod Biol. 2008;137:152-6.

3. Carroli G, Mignini L. Episiotomy for vaginal birth. Cochrane Database Systematic Review. 2009;21(1):cd000081.

4. Alves GF, Nogueira LS, Varella TC. Dermatology and pregnancy. Anias Brasilieros de Dermatologia. 2005;80:179-86.

5. Chang AL, Agrenado YZ, Kimball AB. Risk factors associated with striae gravidarum. Journal of the American Academy of Dermatology. 2004;51:881-5.

6. Osman H, Rubeiz N, Tamim H, Nassar AH. Risk factors for the development of striae gravidarum. American Journal of Obstetrics and Gynecology. 2007;62:1-5.

7. Atwal GS, Manku LK, Griffiths CE, Polson DW. Striae gravidarum in primiparae. $\mathrm{Br} \mathrm{J}$ Dermatol. 2006;155:965-9.

8. Angioli R, Gomez-Matin O, Cantuaria G, O'Sullivan MJ. Severe perineal lacerations during vaginal delivery: the University of Miami experience. Am J Obstet Gynecol. 2000;182:1083-5.

9. Klein MC, Gauthier RJ, Jorgensen SH, Robbins JM, Kaczorowski J, Johnson B, Corriveau M, Westreich R, Waghorn K, Gelfand MM, et al. Does episiotomy prevent perineal trauma and pelvic floor relaxation? Online J Curr Clin Trials. 1992 Jul;Doc No 10:[6019 words; 65 paragraphs].

10. Helwig JT, Thorp JM Jr, Bowes WA Jr. Does midline episiotomy increase the risk of third- and fourth-degree lacerations in operative vaginal deliveries? Obstet Gynecol. 1993 Aug;82(2):276-9.

11. Thorp JM Jr, Bowes WA Jr, Brame RG, et al. Selective use of midline episiotomy: effect on perineal trauma. Obstet Gynecol. 1987;70:240-4. 
12. Gass MS, Dunn C, Stys SJ. Effect of episiotomy on the frequency of vaginal outlet lacerations. J Reprod Med. 1986 Apr;31(4):240-4.

13. Borghi J, Fox-Rushby J, Bergel E, Abalos E, Hutton G, Carroli G. The cost-effectiveness of routine versus restrictive episiotomy in Argentina. Am J Obstet Gynecol. 2002 Feb;186(2):221-8.

DOI: $10.5455 / 2320-1770 . i j r \operatorname{cog} 20140342$

Cite this article as: Kapadia S, Kapoor S, Parmar K, Patadia K, Vyas M. Prediction of perineal tear during childbirth by assessment of striae gravidarum score. Int J Reprod Contracept Obstet Gynecol 2014;3:208-12. 